\title{
A community-based survey of Toxoplasma gondii infection among pregnant women in rural areas of Taiz governorate, Yemen: the risk of waterborne transmission
}

\author{
Mohammed A. K. Mahdy ${ }^{1,2^{*}}$, Lina M. Q. Alareqi ${ }^{3}$, Rashad Abdul-Ghani ${ }^{1,2}$, Samira M. A. Al-Eryani ${ }^{2}$, \\ Abdullah A. Al-Mikhlafy ${ }^{4}$, Abdulsalam M. Al-Mekhlafi ${ }^{2}$, Fawzya Alkarshy ${ }^{5}$ and Rohela Mahmud ${ }^{3}$
}

\begin{abstract}
Background: Toxoplasma gondii is a zoonotic coccidian parasite causing morbidity and mortality. In Yemen, $T$. gondii infection has been reported among pregnant women seeking healthcare in the main cities. However, no data are available on the prevalence of $T$. gondii infection and its associated risk factors among pregnant women in the rural communities of the country. Thus, the present study aimed to determine the seroprevalence of $T$. gondii and identify its risk factors among pregnant women in the rural communities of Taiz governorate, Yemen.

Methods: A total of 359 pregnant women living in the rural communities of Taiz governorate were enrolled in this study by house-to-house visits. Data were collected using a pre-designed questionnaire, and blood samples were collected and tested for the detection of anti- T. gondii IgM and lgG antibodies by enzyme-linked immunosorbent assay.

Results: The prevalence of $T$. gondii infection among pregnant women in this study was $46.2 \%(166 / 359)$. Bivariate analysis identified the age of $\geq 30$ years (odds ratio $[\mathrm{OR}]=1.7 ; 95 \%$ confidence interval $[\mathrm{Cl}]=1.09-2.65, P=0.019$ ) and unimproved water sources $(\mathrm{OR}=2.2 ; 95 \% \mathrm{Cl}=1.10-4.55, P=0.023)$ as factors associated with $T$. gondii infection among pregnant women. The multivariable analysis, however, identified unimproved water sources as an independent risk factor (adjusted $\mathrm{OR}=2.4 ; 95 \% \mathrm{Cl}=1.16-5.0, P=0.018$ ) associated with $T$. gondii infection among pregnant women.
\end{abstract}

Conclusions: Pregnant women in the rural communities of Taiz, Yemen are at high risk of contracting T. gondii infection. Unimproved water sources (wells, water streams and water tanks) are significantly associated with T. gondii infection and should be considered in prevention and control strategies, especially among pregnant women.

Keywords: Toxoplasma gondii, Rural communities, Pregnant women, Waterborne transmission, Yemen

\section{Multilingual abstracts}

Please see Additional file 1 for translations of the abstract into the five official working languages of the United Nations.

\section{Background}

Toxoplasma gondii is a zoonotic coccidian parasite that is distributed worldwide, with about a third of the

\footnotetext{
* Correspondence: Alsharaby9@yahoo.com

${ }^{1}$ Tropical Disease Research Center, University of Science and Technology, Sana'a, Yemen

'Department of Parasitology, Faculty of Medicine and Health Sciences, Sana'a University, Sana'a, Yemen

Full list of author information is available at the end of the article
}

human population having a chronic infection $[1,2]$. Humans are infected by ingesting oocysts directly or in contaminated water or food, or by eating undercooked meat containing tissue cysts $[3,4]$. Blood transfusion and organ transplantation are also potential routes of transmission [5]. T. gondii infection is asymptomatic in healthy adults but can cause severe complications in immunocompromised individuals [6]. Moreover, primary infection in pregnant women may lead to congenital toxoplasmosis, with the highest incidence rates being reported in low-income African countries and parts of the Middle East [7]. Congenital toxoplasmosis following primary infection during pregnancy is the most 
important aspect of human toxoplasmosis, possibly leading to abortion, stillbirth, congenital anomalies as well as neurological and ocular complications [1]. T. gondii seroprevalence among pregnant women or females of reproductive age is high in different parts of the world. In their review on the global status of $T$. gondii infection among pregnant women, Pappas et al. [8] cited T. gondii seroprevalence rates of $6.1-77.5 \%$ among women who were pregnant or of reproductive age in the Americas, 8.2-63.2\% in Europe, $25.3-75.2 \%$ in Africa and $0.8->$ $60 \%$ in Asia and Oceania.

Diagnosis of $T$. gondii infection is commonly established by serological testing for immunoglobulin $M$ (IgM) and immunoglobulin G (IgG) antibodies [2]. IgM antibodies are produced in the first week after infection and decline to undetectable levels within months. Although its diagnostic value in determining acute infection is limited as it may persist for years [9, 10], IgM negativity rules out acute infection. IgG antibodies appear 2-3 weeks after IgM antibodies, and their levels then decrease, resulting in lifelong persistence of low residual titers [11]. IgG avidity was introduced to overcome false-positive IgM reactions and the inability of IgG to discriminate between past and recent infections, where low-avidity IgG antibodies usually indicate a recent infection [12, 13]. However, because low-avidity IgG antibodies may persist for long periods of time, this hampers their utility to diagnose acute infection $[14,15]$. For more correct diagnosis of $T$. gondii infection, a clinical situation-based diagnostic strategy has been suggested. However, the detection of IgG and IgM antibodies is still the most commonly used approach for primary screening $[16,17]$. This could be further improved by the development of diagnostic kits based on recombinant multi-epitope antigens [17] or on immunoreactive proteins $[18,19]$.

In Yemen, the large population of stray cats represents a significant source of environmental contamination because of the oocysts they shed in their faeces. Oocystcontaminated water sources put the entire human population at risk of infection [3]. Nevertheless, no data are available on the prevalence of $T$. gondii infection and its associated risk factors in the rural communities of Yemen, especially among pregnant women, with previous reports focusing primarily on hospital-based cases in urban communities [20, 21]. Thus, this study aimed to investigate the prevalence and risk factors for T. gondii infection among pregnant women living in the rural communities of Taiz, Yemen.

\section{Methods}

\section{Study area}

A cross-sectional, community-based survey was conducted in 56 easily accessible rural areas of Taiz, Yemen, in the period from May 2012 to February 2014. Taiz is the most populous city in Yemen located at the geographical coordinates of $13^{\circ} 34^{\prime} 44^{\prime \prime} \mathrm{N} 44^{\circ} 01^{\prime} 19^{\prime \prime} \mathrm{E}$. It is situated at an elevation of about 1400 metres above the Red Sea level, southwest of Sana'a (see Fig. 1).

All pregnant women in the surveyed communities were invited to participate in this study by house-tohouse visits. The coordinates of pregnant women's houses were determined using Global Positioning System software (GPSMAP ${ }^{\circ}$ 60CSx, Garmin, Tonopah, AZ, USA).

\section{Data and blood collection}

A pre-designed questionnaire was used to collect data about the participating women's age, gestational age, education level, employment, type of water source that their household uses and whether they reared animals. They were also asked about their habit of chewing khat, the leaves of the shrub Catha edulis, which are chewed like tobacco.

Water sources were classified into improved water sources (piped water connected to the household) and unimproved water sources (wells, water streams and water tanks), following the criteria of UNICEF/WHO Joint Monitoring Programme for Water Supply and Sanitation [22]. Data were also collected about the participants' history of miscarriage.

Blood specimens were collected in pre-labelled tubes, and sera were separated after clotting by centrifugation at 3000 rounds per minute for $10 \mathrm{~min}$. Sera were then preserved at $-20{ }^{\circ} \mathrm{C}$ until the performance of serological investigations.

\section{Serological investigations}

Sera were tested for anti- T. gondii IgM and IgG antibodies using commercial enzyme-linked immunosorbent assay (ELISA) kits (NovaTec Immundiagnostica $\mathrm{GmbH}$, Dietzenbach, Germany), as according to the manufacturer's instructions. Antibody titers were determined following the normal range established by the manufacturer, and presented as positive or negative. Positive and negative controls were included in each of the ELISA tests to ensure the integrity of the reagents and technical performance.

\section{Statistical analysis}

Data were entered and analysed using the IBM SSPS Statistics for Windows, version 22.0 (IBM Corp., Armonk, NY, USA). Descriptive data obtained from the questionnaires and laboratory investigations were presented as frequencies and percentages. Differences and associations between categorical variables were tested using the Pearson's chi-square test. Unadjusted odds ratios (ORs) and $95 \%$ confidence intervals (CIs) were reported in the 


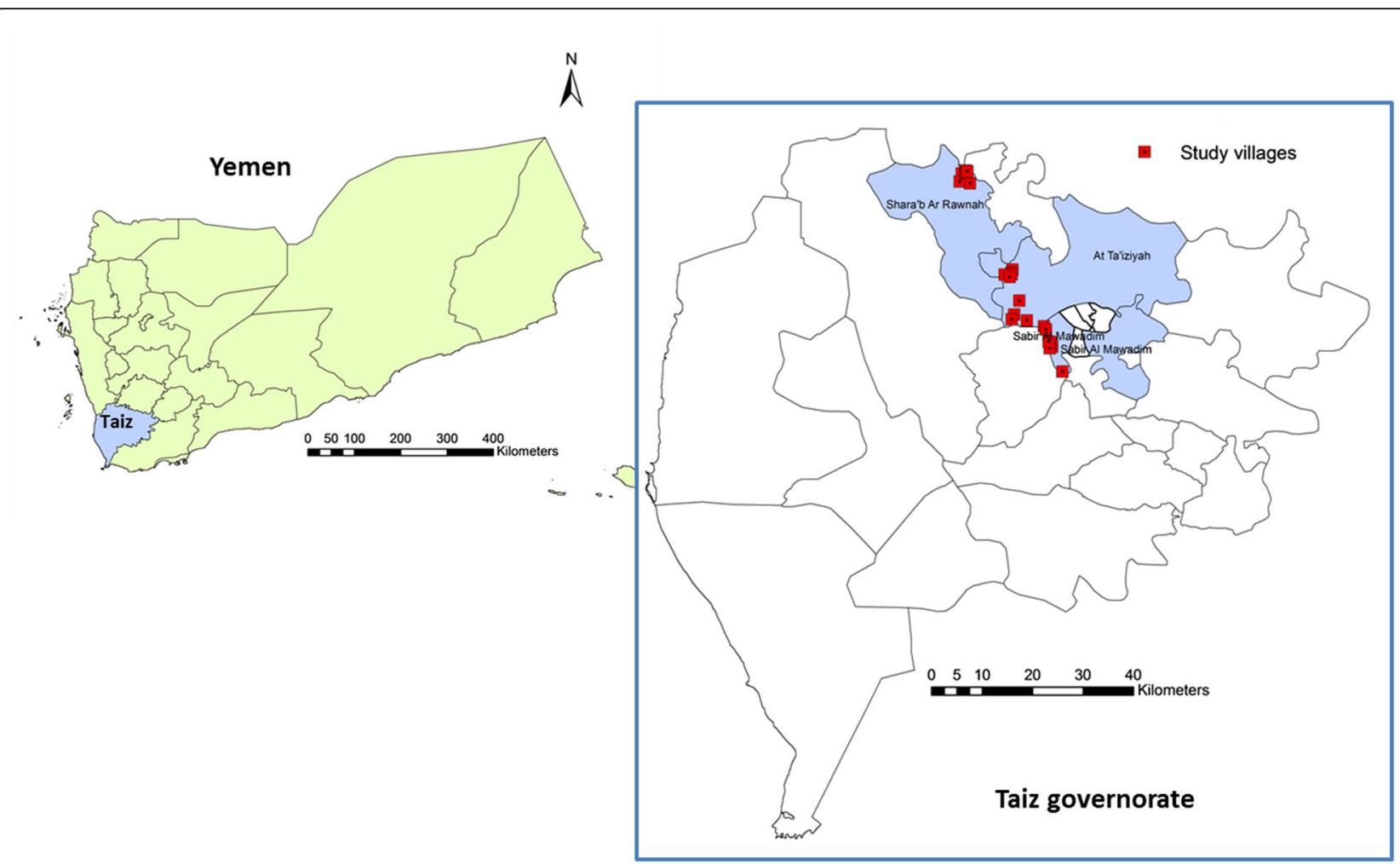

Fig. 1 Map of Yemen showing the location of Taiz governorate and the study area

bivariate analysis. Variables with $P$-values $<0.08$ were entered into a forward logistic regression model to calculate the adjusted ORs and identify the independent predictors of infection. $P$-values $<0.05$ were considered statistically significant.

\section{Results}

\section{Characteristics of the study population}

Of the pregnant women enrolled in the present study, $31.5 \%, 34.9 \%$ and $33.5 \%$ were in the first, second and third trimesters, respectively. The median age was 26 years (interquartile range: $22-30$ ). More than half of the women reported rearing animals and having the habit of chewing khat. History of miscarriage was reported by $45.7 \%$ of the women, and the majority of the women's households had unimproved water sources (see Table 1).

\section{T. gondii seropositivity and associated risk factors among the study population}

The seroprevalence of $T$. gondii infection among pregnant women as indicated by IgG antibodies was $46.2 \%$ (166/359). However, anti-T. gondii IgM antibodies were detected in 12 samples (3.3\%): combined with anti- $T$. gondii IgG antibodies in 1.4\% (5/359) and alone in 1.9\% (7/359) of samples. Bivariate analysis showed a significant association between $T$. gondii infection and the age group of $\geq 30$ years old $(\mathrm{OR}=1.7,95 \% \mathrm{CI}=1.09-2.65$, $P=0.019)$. Pregnant women living in households with unimproved water sources had a twofold higher risk of being infected with $T$. gondii compared with those using improved water sources $(\mathrm{OR}=2.2 ; 95 \% \mathrm{CI}=1.10-4.55$, $P=0.023)$. Khat chewers showed a higher, but statistically non-significant, rate of contracting $T$. gondii infection than non-chewers $(\mathrm{OR}=1.48 ; 95 \% \mathrm{CI}=0.96-2.27$, $P=0.076$ ). On the other hand, the participants' gestational age, parity, previous history of miscarriage, contact with animals, education status and employment status were not significantly associated with $T$. gondii infection. The multivariable analysis identified unimproved water sources as the independent risk factor associated with $T$. gondii infection among pregnant women (adjusted $\mathrm{OR}=2.4 ; 95 \% \mathrm{CI}=1.16-5.0, P=0.018$ ) (Table 1).

\section{Discussion}

This is the first community-based survey to determine the seroprevalence of $T$. gondii infection and its associated risk factors among pregnant women in the rural areas of Yemen. Past exposure to T. gondii infection was found in $46.2 \%$ of the surveyed pregnant women in the Taiz governorate, as revealed by the seropositivity of IgG antibodies. IgM seronegativity among the majority of IgG-positive women rules out acute infection. This 
Table 1 Bivariate analysis of factors associated with T. gondii lgG seropositivity among pregnant women in the rural communities of Taiz, Yemen (2012-2014)

\begin{tabular}{|c|c|c|c|c|}
\hline Variable & $N$ & $n(\%)$ & OR $(95 \% \mathrm{Cl})$ & $P$-value \\
\hline \multicolumn{5}{|l|}{ Age (years) } \\
\hline $14-29$ & 241 & $101(41.9)$ & 1 & \\
\hline$\geq 30$ & 118 & $65(55.1)$ & $1.7(1.09-2.65)$ & 0.019 \\
\hline \multicolumn{5}{|l|}{ Education $(n=356)$} \\
\hline Primary school or above & 67 & $32(47.8)$ & 1 & \\
\hline No formal education & 289 & $131(45.3)$ & $0.9(0.53-1.54)$ & 0.719 \\
\hline \multicolumn{5}{|l|}{ Parity } \\
\hline$\leq 2$ & 109 & $48(44.0)$ & 1 & \\
\hline$>2$ & 250 & $118(47.2)$ & $1.4(0.72-1.79)$ & 0.580 \\
\hline \multicolumn{5}{|l|}{ Gestational age $(n=355)$} \\
\hline First trimester & 112 & $54(48.2)$ & 1 & \\
\hline Second trimester & 124 & $54(43.5)$ & $0.8(0.50-1.38)$ & 0.470 \\
\hline Third trimester & 119 & $55(46.2)$ & $0.9(0.55-1.55)$ & 0.760 \\
\hline \multicolumn{5}{|l|}{ History of miscarriage $(n=356)$} \\
\hline No & 193 & $86(44.6)$ & 1 & 0.613 \\
\hline Yes & 163 & $77(47.2)$ & $1.1(0.73-1.69)$ & \\
\hline \multicolumn{5}{|l|}{ Employment $(n=356)$} \\
\hline Employed & 10 & $3(30.0)$ & 1 & \\
\hline Unemployed & 346 & $160(46.2)$ & $2.0(0.51-7.89)$ & 0.309 \\
\hline
\end{tabular}

Type of household water source $(n=357)$

$\begin{array}{lllll}\text { Improved } & 41 & 12(29.3) & 1 & \\ \text { Unimproved } & 316 & 152(48.1) & 2.2(1.10-4.55) & 0.023^{\mathrm{a}}\end{array}$

Storing water at household $(n=315)$

$\begin{array}{lllll}\text { No } & 43 & 21(48.8) & 1 & \\ \text { Yes } & 272 & 121(44.5) & 0.8(0.44-1.60) & 0.594\end{array}$

Rearing animals $(n=351)$

$\begin{array}{lllll}\text { No } & 150 & 63(42.0) & 1 & \\ \text { Yes } & 201 & 96(47.8) & 1.3(0.82-1.93) & 0.283\end{array}$

Chewing khat $(n=354)$

$\begin{array}{lllll}\text { No } & 141 & 56(39.7) & 1 & \\ \text { Yes } & 213 & 105(49.3) & 1.48(0.96-2.27) & 0.076\end{array}$

$N$, number examined, $n$, number of IgG-positive women

${ }^{a}$ Confirmed as an independent risk factor by multivariable analysis

finding is comparable to that recently reported $(44 \% ; 59$ / 134) among pregnant women admitted to an obstetrics clinic in urban Taiz [21]. It remains uncertain whether the very low seropositivity rates of IgM antibodies, either alone or in combination with IgG antibodies, indicate an acute infection among pregnant women in the present study because neither seroconversion nor IgG avidity testing was performed. About a half of the pregnant women were IgG-negative and are, therefore, not immune to infection. Thus, there is a high risk of acquiring primary infection with $T$. gondii during pregnancy, increasing the risk of congenital toxoplasmosis [16].

The present study revealed a significant association between $T$. gondii infection and unimproved water sources in the rural communities of Taiz. The infection was about twofold more likely in pregnant women using unimproved water sources compared with those using improved water sources. This finding is consistent with a report from the rural communities of Guatemala, which revealed a significant association between the high prevalence of $T$. gondii infection and drinking unfiltered well water [23]. Similarly, the association of T. gondii infection with drinking unboiled well water was also reported from rural Poland [24], which was thereafter confirmed by the isolation of parasite oocysts from drinking water in the same rural communities [25]. Moreover, water has been suggested as a source of $T$. gondii infection in several other studies conducted in different countries such as Brazil, Turkey, São Tomé and Príncipe and Taiwan [26-29].

The association between unimproved water sources and past exposure to T. gondii infection in the present study could be attributed to the large population of stray cats in the rural communities of Yemen. Cats shed millions of oocysts that are resistant to destruction and can survive in the soil for long periods under ordinary environmental conditions [3]. Water sources can be contaminated by runoff from the soil contaminated by excreta of infected cats, leading to widespread dissemination of $T$. gondii infection. Oocyst-mediated waterborne transmission of $T$. gondii has been reported in different parts of the world, including Atlanta, Georgia [30], Panama [31], Canada [32], Brazil [33] and Ethiopia [34].

The significantly higher infection rate of $T$. gondii among pregnant women aged 30 years or above in the present survey is consistent with those reported in previous studies elsewhere [35-38]. This indicates a higher risk of exposure of older women to T. gondii infection, which could possibly be due to the fact that older women conduct more activities involving contact with unimproved water sources. A previous study showed that adult women in rural Yemen are the main water bearers (Mahdy et al., unpublished data). This postulation is supported by the significant association between both older age and unimproved water sources with $T$. gondii infection observed in the present study.

The habit of chewing khat was not significantly associated with past exposure to $T$. gondii infection in this study, though a larger proportion of those infected with $T$. gondii were khat chewers. The role of unwashed vegetables as vehicles for transmitting $T$. gondii oocysts is well documented [4, 39, 40]. Khat could also play this transmission role, as it may become contaminated with oocysts from the environment or if it is washed with 
contaminated water. It is noteworthy that the local customs of cooking meat under high pressure and eating well-cooked meat exclude the possibility of $T$. gondii infection through eating meat in these rural communities. In addition, animal contact does not appear to be a predictor of $T$. gondii infection among pregnant women, as revealed by the absence of a significant association between rearing animals and $T$. gondii infection in the present study.

Parity, gestational age, education status, employment status and previous history of miscarriage were not significantly associated with $T$. gondii infection among pregnant women in this study. However, in a recent study [21], previous miscarriages among women in Taiz were found to be associated with $T$. gondii infection. This could be attributed to the fact that a large proportion of pregnant women in that clinic-based study might have sought medical care after abortion.

\section{Conclusions}

In conclusion, about half of the pregnant women in the rural communities of Taiz governorate surveyed in this study showed a previous exposure to $T$. gondii infection, with unimproved water sources determined as being the significant source of infection. Therefore, intervention strategies for prevention and control should target such sources. In addition, educating pregnant women about the importance of boiling water could be an effective control measure in these rural communities.

\section{Additional file}

Additional file 1: Multilingual abstracts in the five official working

languages of the United Nations. (PDF $922 \mathrm{~kb}$ )

\section{Abbreviations}

Cl: Confidence interval; ELISA: Enzyme-linked immunosorbent assay; IgG: Immunoglobulin G; IgM: Immunoglobulin M; OR: Odds ratio; SPSS: Statistical Packages for Social Sciences

\section{Acknowledgements}

The authors would like to thank the pregnant women who participated in this study and the staff of the health facilities in the rural communities of Taiz for their cooperation during the field trips.

\section{Funding}

This work was supported by a UM High Impact Research Grant (H-20001-00E00051) from the Ministry of Higher Education, Malaysia.

\section{Availability of data and materials}

All relevant data are presented within the article or the cited papers.

\section{Authors' contributions}

MAKM and RM designed the study. LMQA and FA carried out field trips and the laboratory work. MAKM analysed and interpreted the data. MAKM and RA drafted the paper. MAKM, RA, SMAA, AA-M, AMA and RM revised and edited the paper. All authors read and approved the final paper.

\section{Competing interests}

The authors declare that they have no competing interests.
Consent for publication

Not applicable.

\section{Ethics approval and consent to participate}

The study protocol was reviewed and approved by the Ethics Committee of the University of Science and Technology, Yemen. Participation was voluntary and written informed consent was obtained from each participating pregnant woman prior to the commencement of the study.

\section{Author details \\ ${ }^{1}$ Tropical Disease Research Center, University of Science and Technology, Sana'a, Yemen. 'Department of Parasitology, Faculty of Medicine and Health Sciences, Sana'a University, Sana'a, Yemen. ${ }^{3}$ Department of Parasitology, Faculty of Medicine, University of Malaya, 50603 Kuala Lumpur, Malaysia. ${ }^{4}$ Department of Community Medicine, Faculty of Medicine, University of Science and Technology, Sana'a, Yemen. ${ }^{5}$ Yemeni-Swedish Hospital, Ministry of Public Health and Population, Taiz, Yemen.}

Received: 29 December 2015 Accepted: 13 January 2017

Published online: 13 February 2017

\section{References}

1. Moncada PA, Montoya JG. Toxoplasmosis in the fetus and newborn: an update on prevalence, diagnosis and treatment. Expert Rev Anti Infect Ther. 2012:10:815-22.

2. Liu Q, Wang ZD, Huang SY, Zhu XQ. Diagnosis of toxoplasmosis and typing of Toxoplasma gondii. Parasit Vectors 2015:8:292.

3. Jones JL, Dubey JP. Waterborne toxoplasmosis-recent developments. Exp Parasitol. 2010;124:10-25.

4. Jones JL, Dubey JP. Foodborne toxoplasmosis. Clin Infect Dis. 2012;55:845-51.

5. Israelski DM, Remington JS. Toxoplasmosis in the non-AIDS immunocompromised host. Curr Clin Top Infect Dis. 1993;13:322-56.

6. Nash G, Kerschmann RL, Herndier B, Dubey JP. The pathological manifestations of pulmonary toxoplasmosis in the acquired immunodeficiency syndrome. Hum Pathol. 1994;25:652-8.

7. Torgerson PR, Mastroiacovo P. The global burden of congenital toxoplasmosis: a systematic review. Bull World Health Organ. 2013;91:501-8.

8. Pappas G, Roussos N, Falagas ME. Toxoplasmosis snapshots: global status of Toxoplasma gondii seroprevalence and implications for pregnancy and congenital toxoplasmosis. Int J Parasitol. 2009;39:1385-94.

9. Dhakal R, Gajurel K, Pomares C, Talucod J, Press CJ, Montoya JG. Significance of a positive Toxoplasma immunoglobulin $\mathrm{M}$ test result in the United States. J Clin Microbiol. 2015:53:3601-5.

10. Montoya JG. Laboratory diagnosis of Toxoplasma gondii infection and toxoplasmosis. J Infect Dis. 2002;185 Suppl 1:S73-82.

11. Robert-Gangneux F, Darde ML. Epidemiology of and diagnostic strategies for toxoplasmosis. Clin Microbiol Rev. 2012;25:264-96.

12. Liesenfeld O, Press C, Montoya JG, Gill R, Isaac-Renton JL, Hedman K, Remington JS. False-positive results in immunoglobulin M (IgM) Toxoplasma antibody tests and importance of confirmatory testing: the Platelia Toxo lgM test. J Clin Microbiol. 1997;35:174-8.

13. Candolfi E, Pastor R, Huber R, Filisetti D, Villard O. lgG avidity assay firms up the diagnosis of acute toxoplasmosis on the first serum sample in immunocompetent pregnant women. Diagn Microbiol Infect Dis. 2007;58:83-8.

14. Villard O, Breit L, Cimon B, Franck J, Fricker-Hidalgo H, Godineau N, et al. Comparison of four commercially available avidity tests for Toxoplasma gondii-specific lgG antibodies. Clin Vaccine Immunol. 2013;20:197-204.

15. Murat JB, L'Ollivier C, Fricker Hidalgo $H$, Franck J, Pelloux $H$, et al. Evaluation of the new Elecsys Toxo lgG avidity assay for toxoplasmosis and new insights into the interpretation of avidity results. Clin Vaccine Immunol. 2012;19:1838-43.

16. Murat JB, Hidalgo HF, Brenier-Pinchart MP, Pelloux H. Human toxoplasmosis: which biological diagnostic tests are best suited to which clinical situations? Expert Rev Anti Infect Ther. 2013;11:943-56.

17. Hajissa K, Zakaria R, Suppian R, Mohamed Z. Design and evaluation of a recombinant multi-epitope antigen for serodiagnosis of Toxoplasma gondii infection in humans. Parasit Vectors. 2015:8:315.

18. Sonaimuthu P, Fong MY, Kalyanasundaram R, Mahmud R, Lau YL. Serodiagnostic evaluation of Toxoplasma gondii recombinant rhoptry antigen 8 expressed in E. coli. Parasit Vectors 2014;7:297. 
19. Wang $\mathrm{Y}$, Yin $\mathrm{H}$. Research advances in microneme protein 3 of Toxoplasma gondii. Parasit Vectors 2015;8:384.

20. Saleh MM AHAL-S, Qaed AA. Seroprevalence and incidence of Toxoplasma gondii among apparently healthy and visually or hearing disabled children in Taiz City, Yemen. Korean J Parasitol. 2010;48:71-3.

21. Saif N, Al Ameeri G, Alhweesh M, Alkadasi M, Zaid AA. Seroprevalence of toxoplasmosis in pregnant women in Taiz-Yemen. Int J Curr Microbiol App Sci. 2014;3:680-90.

22. Joint Monitoring Programme for Water Supply and Sanitation. Core questions on drinking water and sanitation for household surveys. Geneva: World Health Organization and UNICEF; 2006.

23. Jones JL, Lopez B, Alvarez Mury M, Wilson M, Klein R, Luby S, et al. Toxoplasma gondii infection in rural Guatemalan children. Am J Trop Med Hyg. 2005;72:295-300.

24. Sroka J, Wojcik-Fatla A, Dutkiewicz J. Occurrence of Toxoplasma gondii in water from wells located on farms. Ann Agric Environ Med. 2006;13:169-75.

25. Sroka J, Wojcik-Fatla A, Szymanska J, Dutkiewicz J, Zajac V, Zwolinski J. The occurrence of Toxoplasma gondii infection in people and animals from rural environment of Lublin region - estimate of potential role of water as a source of infection. Ann Agric Environ Med. 2010;17:125-32.

26. Heukelbach J, Meyer-Cirkel V, Moura RC, Gomide M, Queiroz JA, Saweljew P, et al. Waterborne toxoplasmosis, northeastern Brazil. Emerg Infect Dis. 2007; 13:287-9.

27. Ertug S, Okyay P, Turkmen M, Yuksel H. Seroprevalence and risk factors for Toxoplasma infection among pregnant women in Aydin province, Turkey. BMC Public Health. 2005:5:66.

28. Hung CC, Fan CK, Su KE, Sung FC, Chiou HY, Gil V, et al. Serological screening and toxoplasmosis exposure factors among pregnant women in the Democratic Republic of São Tomé and Príncipe. Trans R Soc Trop Med Hyg. 2007;101:134-9.

29. Lin YL, Liao YS, Liao LR, Chen FN, Kuo HM, He S. Seroprevalence and sources of Toxoplasma infection among indigenous and immigrant pregnant women in Taiwan. Parasitol Res. 2008;103:67-74.

30. Teutsch SM, Juranek DD, Sulzer A, Dubey JP, Sikes RK. Epidemic toxoplasmosis associated with infected cats. N Engl J Med. 1979:300:695-9.

31. Benenson MW, Takafuji ET, Lemon SM, Greenup RL, Sulzer AJ. Oocysttransmitted toxoplasmosis associated with ingestion of contaminated water. N Engl J Med. 1982;307:666-9.

32. Bowie WR, King AS, Werker DH, Isaac-Renton JL, Bell A, Eng SB, et al. Outbreak of toxoplasmosis associated with municipal drinking water. The BC Toxoplasma Investigation Team. Lancet. 1997;350:173-7.

33. de Moura L, Bahia-Oliveira LM, Wada MY, Jones JL, Tuboi SH, Carmo EH, et al. Waterborne toxoplasmosis, Brazil, from field to gene. Emerg Infect Dis. 2006;12: 326-9.

34. Gebremedhin EZ, Tadesse G. A meta-analysis of the prevalence of Toxoplasma gondii in animals and humans in Ethiopia. Parasit Vectors 2015; 8:291

35. Nissapatorn V, Suwanrath C, Sawangjaroen N, Ling LY, Chandeying V. Toxoplasmosis-serological evidence and associated risk factors among pregnant women in southern Thailand. Am J Trop Med Hyg. 2011:85:243-7.

36. Al-Nahari AM, Al-Tamimi AS. Seroprevalence of anti Toxoplasma gondii lgG and IgM among pregnant women in Sana'a capital and Capital Trusteeship. Sci J King Faisal Uni. 2010;11:1431.

37. Muqbil NA, Alqubatii MA. Seroprevalence of toxoplasmosis among women in Aden city, Yemen. Arch Biomed Sci. 2014;2:42-50.

38. Moura FL, Amendoeira MR, Bastos OM, Mattos DP, Fonseca AB, Nicolau JL, et al. Prevalence and risk factors for Toxoplasma gondii infection among pregnant and postpartum women attended at public healthcare facilities in the City of Niteroi, State of Rio de Janeiro, Brazil. Rev Soc Bras Med Trop. 2013;46:200-7.

39. Pereira KS, Franco RM, Leal DA. Transmission of toxoplasmosis (Toxoplasma gondii) by foods. Adv Food Nutr Res. 2010;60:1-19.

40. Alvarado-Esquivel C, Estrada-Martínez S, Liesenfeld O. Toxoplasma gondii infection in workers occupationally exposed to unwashed raw fruits and vegetables: a case control seroprevalence study. Parasit Vectors 2011;4:235.

\section{Submit your next manuscript to BioMed Central and we will help you at every step:}

- We accept pre-submission inquiries

- Our selector tool helps you to find the most relevant journal

- We provide round the clock customer support

- Convenient online submission

- Thorough peer review

- Inclusion in PubMed and all major indexing services

- Maximum visibility for your research

Submit your manuscript at www.biomedcentral.com/submit
Biomed Central 